\title{
1 The Association between City-level Air Pollution and Frailty among the 2 Elderly Population in China
}

3 Kai Hu ${ }^{a}$, Katherine Keenan ${ }^{a}$, Jo Mhairi Hale ${ }^{a}$, Tobias Börger ${ }^{b}$

$4 \quad$ a Population and Health Research Group, School of Geography and Sustainable Development, University 5 of St Andrews, Fife, KY16 9AL, UK

$6 \quad{ }^{b}$ Economics Division, University of Stirling, Stirling, FK9 4LA, UK

\section{Introduction}

9 Gross domestic product (GDP) has increased ten-fold in China during the last two decades, quality of life for most of the Chinese population has greatly improved, and their life expectancy has substantially increased as well (Ebenstein et al., 2015). However, the environmental effects of economic development have been a concern to the government and the public (Zhang et al., 2010). Industrial manufacturing is a major source of pollutants, contributing to harmful materials in air, water, soil and food. Among these, air pollution (AP) has attracted a great deal of attention, as most Chinese cities experience air pollution levels above national air quality standards (Wang et al., 2014). The association between AP and poor health is well established. Specifically, studies have found a strong association between exposure to air pollution and reduced life expectancy (Ebenstein et al., 2015), higher levels of respiratory mortality (Richardson et al., 2011), chronic diseases such as chronic obstructive pulmonary disease (COPD) (Liu et al., 2018; Wang et al., 2018), mental health (Signoretta et al., 2019; Zhong et al., 2017), cognitive health (Zhang et al., 2018), functional health (Sun and Gu, 2008), and self-rated health (Charafeddine and Boden, 2008).

Alongside rising pollution levels, the population of China is ageing rapidly. Projections from the United Nations predict that the proportion of Chinese elderly people aged 65 years and over will more than double in the next 30 years, increasing from $12 \%$ in 2020 to $27 \%$ of the total population in 2050 (Fang et al., 2015; United Nations, 2019). The proportion of the oldest old (those over 80 years) in the Chinese 
population is projected to quadruple by 2050 (United Nations, 2019). Along with extended lifespan typically comes an expansion of physical and cognitive disability (Zeng et al., 2017). As elsewhere, among the elderly population in China there is a high prevalence of co-morbid chronic diseases and multimorbidity (Gu et al., 2017; Lei et al., 2014). Therefore, an adequate assessment of elderly health must go beyond the single-disease model and take account of multiple co-morbid conditions.

Studies focussing on the Chinese elderly population largely confirm the links found between AP and health, demonstrating a link between AP and individual chronic diseases, such as COPD (Wang et al., 2018), heart diseases (Bai et al., 2019), diabetes (C. Liu et al., 2016) and cardiovascular diseases (CVD) factors like hypertension (Liu et al., 2017; Yang et al., 2018). Therefore, it seems likely that air pollution influences elderly health through multiple disease pathways. In this study, we focus on frailty as a multidimensional measure of increased health vulnerability in the elderly population (Fried et al., 2001; Walston et al., 2006). A recent meta-analysis across 13 cohorts suggested that increased frailty is strongly associated with increased mortality (Kojima et al., 2018). Compared with younger adults, the elderly are expected to be more vulnerable to air pollution due to their increased levels of frailty (Fougère et al., 2015), in part because exposure to air pollution will exacerbate existing frailty through many disease mechanisms. There have, however, been only a limited number of studies on air pollution and frailty in elderly populations (García-Esquinas and Rodríguez-Artalejo, 2017). One study has demonstrated that increased air pollution was associated with increased frailty incidence after myocardial infarction (MI) (Myers et al., 2013), and others suggest that frailty moderates associations between air pollution and lung function (Eckel et al., 2012) and adverse events after MI (Gerber et al., 2014).

The overall aim of this study is to investigate the contribution of long- and short-term exposure to AP on frailty incidence among the elderly in China. We advance previous studies in a number of ways. First, to our knowledge this is the first study of the relationship between AP and frailty (a multidimensional health indicator) in the elderly population, whose need for social and medical care leads to important policy implications. Second, we use longitudinal data on frailty, linked to longitudinal information on air pollution, to understand the association between air pollution and changes in frailty 
over time. Third, we make use of this longitudinal data to distinguish the impact of long-term exposure to AP from short-term fluctuations. This may be important as short-term fluctuations can impact different disease pathways (Xiao et al., 2016). Finally, this study contributes to the literature by exploring potential heterogeneities by age, sex, socioeconomic status, interview time, and regional factors such as GDP per capita.

\section{Methods}

\subsection{Study population}

The data used in this study are from the $6^{\text {th }}$ and $7^{\text {th }}$ waves (2011 and 2014) of the Chinese Longitudinal Healthy Longevity Survey (CLHLS 2011 \& 2014). CLHLS started in 1998 and although initially sampled older adults aged $85+$, this was expanded to those aged $65+$ from 2002 . The survey collects personal and family information, self-reports of functional health, lifestyle, diet, psychological health and home care, as well as measures of cognitive health (according to a set of tests about memory, calculation, recall and language). To allow purposive over-sampling of the older population, the strategy of CLHLS is to randomly select some residential areas and then to interview some centenarians (aged over 100) who are living in those areas. The second step is to interview randomly a nonagenarian (aged over 90), an octogenarian (aged over 80) and a respondent aged 65-79, whose residential addresses are close to the centenarians' home. This strategy can ensure that the proportion of centenarians is similar to respondents who are aged over 80 or 90 .

In 2011, the full CLHLS sample size was 9,765. Between 2011 and 2014, 3,699 respondents (37.9\%) attrited due to death (29.5\%) or non-specified reasons (8.4\%). In 2014, the CLHLS added a refreshment sample of 1,126 new respondents (making the 2014 sample $\mathrm{N}=7,192$ ). In the longitudinal data 20112014, restricting the sample to individuals living in cities with AP monitoring stations results in a sample of 7,986 respondents (11,620 observations), living in 123 cities. Missingness on the frailty indicators reduces the number of respondents to 6,943 (9,749 observations). We use listwise deletion for missingness on other predictors (career is missing $4 \%$ and all other predictors are less than $1 \%$ missing). This leaves 6,570 individuals (9,132 observations) from 123 cities in our longitudinal analysis 
and sample of 4,284 from 117 cities in our cross-sectional analysis (only 2014). In the sensitivity analysis where we use geographically weighted regression (GWR) to predict air pollution data, the analytical sample is 8,644 respondents (12,743 observations), living in 174 cities.

Note that we made corrections to approximately $5 \%$ of sample by amending inconsistent reports of gender, education and pre-retirement careers by drawing on data from earlier waves of the survey. All results in the main body of this study are based on the complete case analysis, and GWR data is used to conduct sensitivity analysis in the Supplementary material Table S8/12/13.

\subsection{Frailty index}

To capture an individual's cumulative health deficits most studies calculate the frailty index by a standard comprehensive geriatric assessment (Cesari et al., 2014; Jones et al., 2004). Following the established studies, Gu et al (2009) defined a frailty index using 39 indicators of various dimensions of self-reported health status, cognitive functioning, disability, hearing and visual ability, depression, heart rhythm, and numerous chronic diseases that were collected in the 2002 CLHLS. They validated the measure, demonstrating strong associations with subsequent 3-year mortality (Gu et al., 2009). Based on this research, we constructed the frailty index as an unweighted count of the number of deficits. We excluded 2 of the 39 original indicators (bedsores and duodenal ulcer) because they are missing over 10\% in CLHLS 2011 and 2014, had low prevalence of "yes", and high prevalence of reports of "unknown". We also exclude interviewer-rated health, as its answers may be biased by the researcher effect. Nevertheless, Gu et al (2009) suggested that so long as a reasonable number of indicators from each dimension are included, the index will be robust. There are 36 components of the frailty index including limitations in activities daily living (ADL), limitations in instrumental activities daily living (IADL), functional limitations, cognitive health, self-rated health, hearing, vision, heart rhythm, psychological disorders, number of serious illnesses in the past two years and multiple chronic diseases (hypertension, diabetes, tuberculosis, heart diseases, stroke, bronchitis/asthma, cancer, arthritis and Parkinson's disease). In the CLHLS, cognitive functioning was measured by a Chinese version of the Mini-Mental State Examination (MMSE) with a total score of 30, and respondents with a score of 23 
or lower were considered as cognitively impaired in this paper (Yang and Gu, 2016). All of the components are listed in Supplementary Table S2. Each indicator is recorded as binary except the number of serious illnesses in the past two years (which contains 0 for no illness, 1 for one illness and 2 for two or more illnesses), self-reported whether the respondent ever had a diagnosis. The frailty index then sums the 36 indicators listed above and consequently ranges from 0 to 37.

\subsection{Air Quality Index (AQI)}

This study uses air quality data from the Ministry of Ecology and Environment of China provided for each city for each day for the period from 1st January 2000 to 31st December 2014. The measure of air pollution is the air quality index (AQI), which is calculated based on hourly readings of a set of air pollutants (PM2.5, PM10, SO2, NO2, O3, CO). Higher values of AQI mean more polluted air. AQI is a standardised indicator for air pollution, which has been reported as the local air quality evaluation in 21 nations (Cochran et al., 1992). The association of AQI with the public health burden is used to quantify the negative impacts attributable to air pollution (Stieb et al., 2005), and the validity of using the AQI to assess health impacts of air pollution has been established (Li et al., 2015). We chose AQI as the indicator for air pollution as ambient air consists of an amalgamation of numerous gaseous or solid substances, which prevents isolation of the health effects of individual pollutants (Fougère et al., 2015). The Ministry of Ecology and Environment of China provides more AQI values than other air pollutants records before 2013, although there are still missing values for AQI. In this study, if AQI is missing, but the records of air pollutants (which are the components of AQI) are available (accounting for $5 \%$ of daily records), we computed it using a method provided by Ministry of Ecology and Environment of China (2012). This computation of AQI is a piecewise linear function of the pollutant concentration, using single air pollutants to calculate the individual air quality index (IAQI).

$$
\boldsymbol{I A Q I}_{\boldsymbol{p}}=\frac{I A Q I_{H i}-I A Q I_{L o}}{B P_{H i}-B P_{L o}}\left(C_{p}-B P_{L o}\right)+I A Q I_{L O}
$$


where $I A Q I_{P}$ is the individual air quality index of the pollutant of $P ; C_{p}$ is the pollutant concentration; $B P_{H i}$ is the concentration cut-point over $C_{p} ; B P_{L o}$ is the concentration cut-point below $C_{p} ; I A Q I_{H i}$ is the index cut-point corresponding to $B P_{H i} ; I A Q I_{L o}$ is the index cut-point corresponding to $B P_{L o}$.

$$
A Q I=\max \left\{I A Q I_{1}, I A Q I_{2}, I A Q I_{3}, \ldots, I A Q I_{n}\right\}
$$

We take the value of AQI as the highest value in the list of calculated IAQIs from different pollutants. AQI data is available hourly. For each city, we use the daily average AQI.

This study follows the bulk of the research in defining long-term exposure as more than one-year of exposure (R. Liu et al., 2016; Ma et al., 2016). However, this operationalisation is not unique, and we also analysed longer periods of exposure (2-year and 3-year) in the Supplementary material (crosssectional analysis in Table S4 and S5, longitudinal analysis in Table S9 and S10) to test the robustness of the estimates.

Note that the CLHLS does not provide the exact names of cities but it provides some community information, like population size, administrative area, and GDP. The community information provided in the CLHLS can be used to identify the city of residence in the CLHLS dataset via cross-referencing to Tabulation in the 2010 Population Census of China by County (National Bureau of Statistics of China, 2010). Specifically, we used the population size of a county/district in 2010 to match it to county/district names, as population size is unique for each county/district; these match perfectly. It is then a simple step to locate the city of residence when county/district names are clear, because the county/district is the secondary administrative area within the city in China. After matching, we inserted the cities names into our dataset and then use these names to link the CHLHS dataset to the AQI data.

Due to the limited number of air quality monitoring stations before 2013 in China, over $30 \%$ of CLHLS cities was missing air pollution data (details in the Supplementary material Table S3). Therefore, spatial interpolation for AQI is necessary for this study as a sensitivity analysis. This study used the GWR to interpolate the missing AQI data, which can include more information compared with the traditional interpolation method. GWR characterized the distribution of daily AQI well with the cross-validation $\left(\mathrm{R}^{2}\right)$ of $1235.13(0.379)$, compared with $\mathrm{R}^{2}(0.249)$ in global regression (details in Supplementary 
material Table S1). We also examined the residuals from the GWR (comparing actual and predicted values), by plotting these on a histogram and Q-Q plot, which are normally distributed shown in the Supplementary material Figure S1.

\section{$2.4 Z$-score of $A Q I$}

There is some research suggesting that some the components of our frailty index are related to longterm air pollution exposure (Ranft et al., 2009), while other components are related to both long-term and short-term exposure (Brunekreef and Holgate, 2002; Dauchet et al., 2018). For example, the associations between exposure to air pollution and ADLs, IADLs, and cognitive impairment, which stem from the degeneration of biological functions, have been examined (Kampa and Castanas, 2008). Results suggest cumulative exposure has a more significant effect (Brunekreef and Holgate, 2002). However, short-term exposure to air pollution can lead to some chronic diseases (e.g., bronchitis, stroke) because air pollutants can lead to acute inflammatory responses induced in the respiratory, cardiovascular and blood circulation system (Brunekreef and Holgate, 2002; Scheers et al., 2018). Therefore, this is another reason for adjusting the short-term exposure in our models.

However, the literature is inconsistent in terms of defining short-term exposure. Daily exposure is mostly measured as the short-term exposure but there is little evidence showing that daily exposure effectively captures short-term exposure effects. Thus, this study calculated averages of AQI over a day, week, month and quarter to account for shorter-term exposure and weekly z-score is the main shortterm fluctuation in our analysis as it has been found that there is an association between weekly exposure to air pollution and human health (Karakatsani et al., 2017). We use the z-score to capture short-term exposure calculated as:

$$
z_{-} \text {score }=\frac{\text { Mean }_{\text {short }}-\text { Mean }_{\text {long }}}{S D_{\text {long }}}
$$

Note that the z-score is a relative indicator capturing the relative deviation of the short-term average from the long-term background level. Compared with a similar study that used absolute values of shortand long-term exposure to air pollution simultaneously (Zhang et al., 2018), using the z-score for this study is to decrease the collinearity between them and is beneficial to take into consideration the 
interactive effects. For example, we hypothesize that a spike in air pollution from a higher level of longterm exposure may have different health effects than the same spike (in absolute terms) from a lower level of exposure. Also, the z-score including the variation of long-term AQI can capture the exposure to air pollution better.

In measuring short- and long-term exposure to air pollution, we used the interview date as the end of duration of exposure and then calculate the mean of AQI for the respective period prior to the interview date: one week ( 7 days), one month (30 days), one quarter (90 days), previous one year (365 days), previous two year (730 days), previous three year (1,095 days) for this study. The advantage of this measure is that it can capture the comparable value for exposure to air pollution. As the interview dates for respondents are different, the exposure window is respondent-specific and dynamic. Figure 1 uses the 1-year exposure to show how the measure works for three exemplary respondents A, B and C.

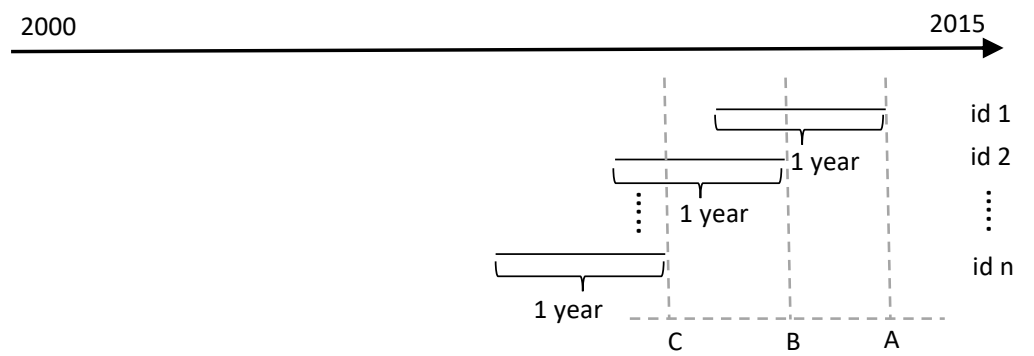

Note: $A, B$, and $C$ mean three respondents interviewed at different dates.

Fig. 1. Hypothetical example of how 1-year exposure to air pollution is calculated

\subsection{AQI category}

In order to distinguish the long-term effects and short-term effects of exposure clearly, in some models the long-term AQI measurements are adjusted for short-term exposures. As for long-term exposure, there are four categories of AQI according to national air quality standards. Considering the cumulative effects of air pollution on health, the concentration cut-point or threshold, of China's AQI is set at the National Ambient Air Quality Standards (NAAQS) (Ruggieri and Plaia, 2012). The standardising transformation separates the AQI into five categories: good (0 - 50), moderate (51 - 100), unhealthy (101 - 150), very unhealthy (151 - 200) and hazardous (200+). Different from the NAAQS's standard, the AQI category in this study is adjusted into four groups because its distribution is skewed, and there 
206

207

are few respondents living in the most polluted area. The detailed index value of categories is shown in Table 1 below.

Table 1 Sub-index of the Air Quality Index (AQI) in China

\begin{tabular}{ccccc}
\hline AQI categories & $\begin{array}{c}\text { AQI 1 } \\
\text { Good }\end{array}$ & $\begin{array}{c}\text { AQI 2 } \\
\text { Moderate }\end{array}$ & $\begin{array}{c}\text { AQI 3 } \\
\text { Unhealthy }\end{array}$ & $\begin{array}{c}\text { AQI 4 } \\
\text { Very unhealthy }\end{array}$ \\
\hline Index value & $0-50$ & $51-75$ & $76-100$ & $101-$ \\
\hline
\end{tabular}

\subsection{Change in AQI variable}

We also generated a new variable at the city level for change or stability of AQI category between waves. For example, based on the AQI categories above, if one respondent resided in a city with AQI 1 in 2011 but that city had AQI 2 level in 2014, the change of AQI is categorized as 'AQI 1-2'; however, if a respondent was recorded as living in a city with AQI 1 in both waves, the change of AQI is categorized as 'AQI 1-1'. In the data we analysed, we find that all of cities with AQI 1 in 2011 remain the AQI 1 in 2014; for the cities with AQI 2 in 2011,21.55\% cities remain AQI 2, but $66.17 \%$ cities experience AQI 3 and 12.28\% cities are with AQI 4 in 2014. However, most cities with AQI 3 in 2011 record AQI 4 (84.37\%) in 2014, while 10.66\% cities remain, and 4.97\% cities move down to AQI 2.

\subsection{Additional covariates}

We also include a set of control variables that may confound or explain the association between air pollution and later-life health. First, the demographic variables include sex, age and age squared (as continuous measures). Marital status comprises three categories: married and living with their spouse, widowed and single (including separate, never married and divorced respondents). The second set of covariates capture socioeconomic status: education, self-rated economic status and pre-retirement career. The education variable in CLHLS is recorded by years of education; however, as more than $50 \%$ of respondents are without schooling experience, the education variable is divided into two categories: no schooling or some education. Self-rated economic status was collected using the question "How do you rate your economic status compared with others in your local area?" as a 5-point scale (very rich, rich, so so, poor, very poor). Due to small variation of this variable, we combine rich and very rich to 
"rich" and poor and very poor into "poor," thus self-rated economic status has three categories: rich, median and poor. Pre-retirement career is based on self-reports of primary job and includes two categories: white collar (including industrial, governmental, commercial and military personnel) and blue collar (including self-rated employed and agricultural personnel, houseworkers and people who never had paid employment). Some area-level confounding factors are also included: natural logarithm of population density, natural logarithm of GDP per capita, both of which are based on the annual citylevel information.

\subsection{Statistical Models}

To estimate the effects of air pollution on health, we test the association between AQI values and incidence rate of frailty. We start with the cross-sectional analysis using the CLHLS 2014, as this one wave provides more observations linked with AQI data. This allows us to explore the associations of exposure to air pollution with frailty with less missing data. As frailty is a count variable, we use multilevel random-intercept Poisson regression models. Individuals are nested within cities, and the air pollution data, population density, and GDP per capita are city-level predictors. We next conduct a three-level longitudinal analysis based on both CLHLS 2011 and 2014, where person-waves are nested in persons, which are nested in cities. The benefit of the longitudinal analysis is that it reduces confounding from unobserved heterogeneity at both the city and individual level.

Additionally, to assess whether change in AP between 2011 and 2014 was associated with frailty change between 2011 and 2014, we also fitted another set of random-effects models with Poisson distribution, which we fitted on a balanced dataset where everyone took part in both waves. No one in our data had moved cities between 2011 and 2014. We generated a new variable at the city level for change or stability of AQI category between waves. We fitted the random-effects model using this 'change in AQI' variable instead of the main AQI variable, including all of the same covariates, and including a time fixed effect (see Table 5). 
252 Descriptive statistics for the 4,746 CLHLS sample respondents in 2011 and 4,284 in 2014 are presented

253 in Table 2. This shows that there are some differences in the sample characteristics between the two

254 waves of CLHLS. As could be expected with an ageing sample, the frailty score goes up between 2011

255 and 2014, while the proportions male, educated and blue-collar respondents are relatively stable. The

256 proportion of cities recording 'unhealthy' and 'very unhealthy' AQI scores increased over time.

257 Table 2 Sample characteristics for analysis sample created from CLHLS, Ministry of Ecology and 258 Environment of China, and Yearbooks 2011 \& 2014

\begin{tabular}{|c|c|c|c|c|}
\hline & \multicolumn{2}{|l|}{2011} & \multicolumn{2}{|l|}{2014} \\
\hline & Mean \pm SD & $\mathrm{N}(\%)$ & Mean \pm SD & $\mathrm{N}(\%)$ \\
\hline \multicolumn{5}{|l|}{ Individual Level } \\
\hline \multicolumn{5}{|l|}{ Variables from CLHLS } \\
\hline Frailty Score & $7.43 \pm 5.54$ & & $7.22 \pm 5.60$ & \\
\hline \multicolumn{5}{|l|}{$\operatorname{Sex}(\%)$} \\
\hline Male & & $2,214(45.65)$ & & $2,024(47.25)$ \\
\hline Female & & $2,532(54.35)$ & & $2,260(52.75)$ \\
\hline \multicolumn{5}{|l|}{ Age } \\
\hline $65-74$ & & $1,040(21.91)$ & & $737(17.20)$ \\
\hline $75-84$ & & $1,321(27.83)$ & & $1,469(34.29)$ \\
\hline $85-94$ & & $1,372(28.91)$ & & $1,256(29.32)$ \\
\hline $95-104$ & & $1,013(21.34)$ & & $822(19.19)$ \\
\hline \multicolumn{5}{|l|}{ Education (\%) } \\
\hline Educated & & $2,541(53.54)$ & & $2,335(54.51)$ \\
\hline No schooling & & $2,205(46.46)$ & & $1,949(45.49)$ \\
\hline \multicolumn{5}{|l|}{ Pre-retirement career (\%) } \\
\hline White-collar & & $1,223(25.77)$ & & $877(20.47)$ \\
\hline Blue-collar & & $3,523(74.23)$ & & $3,407(79.53)$ \\
\hline \multicolumn{5}{|l|}{ Marital status (\%) } \\
\hline Married & & $1,889(39.80)$ & & $1,712(39.96)$ \\
\hline Single & & $131(2.76)$ & & $116(2.71)$ \\
\hline Widowed & & $3,153(57.44)$ & & $2,456(57.33)$ \\
\hline \multicolumn{5}{|c|}{ Self-rated economic position (\%) } \\
\hline Rich/Very-rich & & $869(18.31)$ & & $725(16.92)$ \\
\hline Median & & $3,271(68.92)$ & & $3,113(72.67)$ \\
\hline Poor/Very poor & & $606(12.77)$ & & $446(10.41)$ \\
\hline Total $N$ & & 4,746 & & 4,284 \\
\hline \multicolumn{5}{|l|}{ City Level } \\
\hline \multicolumn{5}{|l|}{ Variables from MEE } \\
\hline \multicolumn{5}{|l|}{$A Q I(1$-year mean $)(\%)$} \\
\hline $\operatorname{Good}(\mathrm{AQI}=1)$ & & $204(4.30)$ & & $479(11.18)$ \\
\hline Moderate (AQI = 2) & & $3,743(78.87)$ & & $1,011(23.60)$ \\
\hline Unhealthy (AQI = 3) & & $799(16.84)$ & & $1,999(46.66)$ \\
\hline Very unhealthy $(\mathrm{AQI}=4)$ & & - & & $795(18.56)$ \\
\hline AQI Z-score (1-year) & & & & \\
\hline
\end{tabular}




\begin{tabular}{|c|c|c|}
\hline Daily Z-score & $-0.40 \pm 0.66$ & $-0.06 \pm 0.65$ \\
\hline Weekly Z-score & $-0.41 \pm 0.44$ & $-0.08 \pm 0.47$ \\
\hline Monthly Z-score & $-0.41 \pm 0.33$ & $-0.04 \pm 0.29$ \\
\hline Quarterly Z-score & $-0.25 \pm 0.32$ & $0.09 \pm 0.25$ \\
\hline \multicolumn{3}{|l|}{ Variables from Yearbooks } \\
\hline Logarithm of GDP & $10.87 \pm 0.41$ & $10.97 \pm 0.52$ \\
\hline Logarithm of population density & $6.39 \pm 0.51$ & $6.32 \pm 0.54$ \\
\hline Number of cities & 77 & 117 \\
\hline
\end{tabular}

259

260

The results from the cross-sectional analysis are shown in Table 3 (in the Supplementary material Table S6 shows more results from different combinations between long-term exposure and z-score). Model 1 includes all the covariates and the 1-year AQI exposure mean as the long-term measure. Model 2 adds the weekly z-score to adjust for short-term AQI exposure. Model 3 includes an interaction term between long- and short-term exposure. Overall, the results suggest that long-term AQI exposure is more significantly associated with frailty than short-term weekly exposures. The results from Model 1 show that, compared with those exposed to the AQI 1 (good air quality), the estimated effect of exposure to AQI 4 (very unhealthy air quality) is to increase the incidence rate, and therefore the expected score of frailty index in a year period, by about $12.6 \%$ higher, a result significant at the $10 \%$ level. In addition, Model 1 also shows that each extra year of age is associated with an estimated 3.9\% increase in the incidence rate and the incidence-rate ratio for a 10 -year increase in age is estimated as $1.039^{10}=1.466$, corresponding to a $46.6 \%$ increase in the score of frailty index, holding other covariates constant. The estimates also suggest that having some education vs. none is associated with reduced incidence rate (over $5 \%$ ) and that the frailty incidence rate increases by $23.7 \%$ for females relative to males, controlling for the other variables. Similarly, the estimates of self-rated reported economic status show the higher incidence rate of frailty among those with lower economic status. For example, frailty incidence rate increases by $41.4 \%$ for respondents with poor self-rated economic status, compared with rich respondents. However, compared with respondents who held blue-collar jobs before retirement, those who had white-collar jobs have higher incident rate, 1.235 (95\% CI: 1.196, 1.276), of being frail. We tested whether the impact of air pollution varied by socio-economic status by including interaction terms between sociodemographic factors and exposure to air pollution (results show in the Supplementary material Table S7) but there are no significant effects. 
281 Table 3 Incidence rate ratio (95\% Confidence Intervals) and random-effect parameters of cross-sectional

282 impact of 1-year and weekly exposure to air pollution on frailty among Chinese elderly, CLHLS 2014

\begin{tabular}{|c|c|c|c|}
\hline VARIABLES & $\begin{array}{l}\text { Model } 1 \\
\text { Long-term }\end{array}$ & $\begin{array}{c}\text { Model } 2 \\
\text { Model } 1+\text { short-term }\end{array}$ & $\begin{array}{c}\text { Model } 3 \\
\text { Model } 2+\text { Long- \# short- } \\
\text { term }\end{array}$ \\
\hline \multicolumn{4}{|c|}{ Long-term (1-year) (ref: AQI 1(good)) } \\
\hline AQI 2 (Moderate) & $\begin{array}{c}1.109 * \\
(1.012-1.215)\end{array}$ & $\begin{array}{c}1.113^{*} \\
(1.015-1.219)\end{array}$ & $\begin{array}{c}1.130 * * \\
(1.032-1.237)\end{array}$ \\
\hline AQI 3 (Unhealthy) & $\begin{array}{c}1.052 \\
(0.943-1.175)\end{array}$ & $\begin{array}{c}1.071 \\
(0.960-1.196)\end{array}$ & $\begin{array}{c}1.104 \# \\
(0.991-1.231)\end{array}$ \\
\hline AQI 4 (Very unhealthy) & $\begin{array}{c}1.126 \# \\
(0.991-1.279)\end{array}$ & $\begin{array}{c}1.140^{*} \\
(1.004-1.295)\end{array}$ & $\begin{array}{c}1.144^{*} \\
(1.011-1.295)\end{array}$ \\
\hline \multicolumn{4}{|l|}{ Short-term } \\
\hline z-score (Weekly) & & $\begin{array}{c}1.040 * \\
(1.006-1.076)\end{array}$ & $\begin{array}{c}0.947 \\
(0.882-1.018)\end{array}$ \\
\hline \multicolumn{4}{|c|}{ Interaction terms (ref: weekly z-score \# AQI 1) } \\
\hline Weekly z-score \# AQI 2 & & & $\begin{array}{c}1.283 * * * \\
(1.160-1.418)\end{array}$ \\
\hline Weekly z-score \# AQI 3 & & & $\begin{array}{c}1.114^{*} \\
(1.020-1.216)\end{array}$ \\
\hline Weekly z-score \# AQI 4 & & & $\begin{array}{c}0.962 \\
(0.859-1.077)\end{array}$ \\
\hline Female (ref: Male) & $\begin{array}{c}1.146^{* * *} \\
(1.114-1.178)\end{array}$ & $\begin{array}{c}1.147 * * * \\
(1.115-1.179)\end{array}$ & $\begin{array}{c}1.146^{* * *} \\
(1.115-1.179)\end{array}$ \\
\hline Age & $\begin{array}{c}1.039 * * * \\
(1.020-1.058)\end{array}$ & $\begin{array}{c}1.038 * * * \\
(1.020-1.057)\end{array}$ & $\begin{array}{c}1.036 * * * \\
(1.017-1.055)\end{array}$ \\
\hline Age \# Age & $\begin{array}{c}1.000 \\
(1.000-1.000)\end{array}$ & $\begin{array}{c}1.000 \\
(1.000-1.000)\end{array}$ & $\begin{array}{c}1.000 \\
(1.000-1.000)\end{array}$ \\
\hline $\begin{array}{l}\text { Educated } \\
\text { (ref: no schooling) }\end{array}$ & $\begin{array}{c}0.935 * * * \\
(0.907-0.963)\end{array}$ & $\begin{array}{c}0.935 * * * \\
(0.908-0.963)\end{array}$ & $\begin{array}{c}0.933 * * * \\
(0.906-0.961)\end{array}$ \\
\hline $\begin{array}{l}\text { Career } \\
\text { (ref: Blue-collar) }\end{array}$ & $\begin{array}{c}1.235^{* * *} \\
(1.196-1.276)\end{array}$ & $\begin{array}{c}1.234 * * * \\
(1.194-1.274)\end{array}$ & $\begin{array}{c}1.234 * * * \\
(1.195-1.275)\end{array}$ \\
\hline \multicolumn{4}{|c|}{ Self-rated economic (ref: Rich) } \\
\hline Median & $\begin{array}{c}1.076^{* * *} \\
(1.042-1.111)\end{array}$ & $\begin{array}{c}1.077 * * * \\
(1.043-1.112)\end{array}$ & $\begin{array}{c}1.078 * * * \\
(1.044-1.113)\end{array}$ \\
\hline Poor & $\begin{array}{c}1.411 * * * \\
(1.351-1.474)\end{array}$ & $\begin{array}{c}1.412 * * * \\
(1.352-1.475)\end{array}$ & $\begin{array}{c}1.414 * * * \\
(1.354-1.477)\end{array}$ \\
\hline \multicolumn{4}{|l|}{ Marriage (ref: Married) } \\
\hline Single & $\begin{array}{c}1.071 \# \\
(0.991-1.156)\end{array}$ & $\begin{array}{c}1.069 \# \\
(0.990-1.154)\end{array}$ & $\begin{array}{c}1.068 \# \\
(0.989-1.153)\end{array}$ \\
\hline Widowed & $\begin{array}{c}1.024 \\
(0.994-1.055)\end{array}$ & $\begin{array}{c}1.022 \\
(0.992-1.053)\end{array}$ & $\begin{array}{c}1.020 \\
(0.990-1.051)\end{array}$ \\
\hline Logarithm of GDP & $\begin{array}{c}1.037 \\
(0.954-1.128)\end{array}$ & $\begin{array}{c}1.033 \\
(0.951-1.123)\end{array}$ & $\begin{array}{c}1.017 \\
(0.939-1.102)\end{array}$ \\
\hline Logarithm of & 0.997 & 1.004 & 0.994 \\
\hline Population density & $(0.922-1.077)$ & $(0.930-1.085)$ & $(0.923-1.071)$ \\
\hline Constant & $\begin{array}{c}0.208^{* *} \\
(0.0648-0.668)\end{array}$ & $\begin{array}{c}0.206^{* *} \\
(0.0647-0.657)\end{array}$ & $\begin{array}{c}0.280^{*} \\
(0.0896-0.877)\end{array}$ \\
\hline \multicolumn{4}{|l|}{ Random-effect parameters } \\
\hline Between-city Variance & $\begin{array}{c}0.035^{* * *} \\
(0.021-0.049)\end{array}$ & $\begin{array}{c}0.034 * * * \\
(0.020-0.048)\end{array}$ & $\begin{array}{c}0.030^{* * *} \\
(0.018-0.043)\end{array}$ \\
\hline Observations (Individual) & 4,194 & 4,194 & 4,194 \\
\hline Number of cities & 112 & 112 & 112 \\
\hline
\end{tabular}




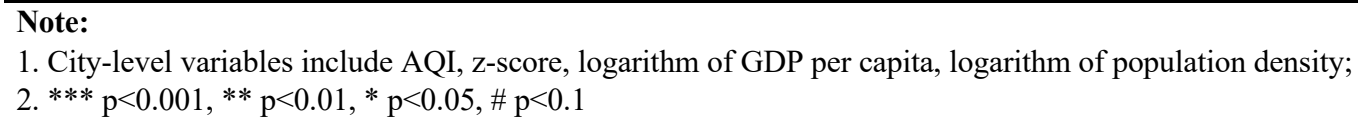

In Model 2, when the short-term exposure term (weekly z-score) is included, the effect of long-term exposure is strengthened in effect size and significance, that is those living in cities with a longer-term AQI levels of 4 had higher frailty scores compared to those with AQI level 1, accounting for short-term fluctuations and other covariates. Specifically, compared with exposure to AQI 1, the estimated effect of exposure to AQI 4 is to increase the incidence rate ratio of frailty index score in a given year period, by about $14.0 \%(\mathrm{p}=0.02)$. Despite a positive coefficient for $\mathrm{z}$-score, this is not significant when adding interaction terms, suggesting that as expected, short-term exposure fluctuations are not associated with the frailty score. The coefficients for marital status, GDP and population density are not significant.

We might also expect that the effect of short-term fluctuations might vary by the overall background level of air pollution exposure, and that short-term fluctuations might affect the long-term mean and then result in biased estimates for long-term exposure. Thus, we added interaction terms between longterm exposure and short-term fluctuations. In Model 3, the interaction effects between weekly z-score and yearly mean AQI are not always significant, providing no evidence that short-term exposure has a differential impact on health at different longer-term air pollution levels.

In addition, all three models show the city-level specific random effects also appear significant, suggesting that a significant amount of variance in frailty can be explained by city-level factors. For example, in Model 3, the city-level random effects present a residual variance between cities $\widehat{\sigma_{u}^{2}}=$ 0.030 with the confidence interval $(0.018-0.043)$. The other coefficients (marital status, logarithm of GDP per capita and logarithm of population density) are not significant at the 5\%-level.

In addition, Tables S4 and S5 in the Supplementary material show effects of 2-year and 3-year exposure. The results are mostly consistent with Table 3 (1-year exposure as the long-term exposure). Results estimated using data obtained by means of GWR interpolation for the cross-sectional analysis also supports the above findings (details shown in Supplementary material Table S8), which provide reassurance that our complete case analysis is not substantially biased. 
Moving to the longitudinal analysis, we present a similar set of models based on the two-wave panel dataset in Table 4 which model the change in frailty between waves. Results clearly show that longterm (1-year) exposure to air pollution has a positive association with frailty, and poorer air quality is associated with higher frailty over a 3-year period from 2011 to 2014. Compared with the crosssectional analysis, the estimates of the frailty score associated with long-term exposure are much bigger and more significant. Specifically, in Model 3, compared with those exposed to the AQI 1 (good air quality), the estimated effect of exposure to AQI 4 (very unhealthy air quality) is to increase the incidence rate, and therefore the expected score of frailty index in a year period, by about $23.3 \%$ $(p=0.003)$. In terms of the weekly z-score, Model 2 shows that the estimated effect of increasing weekly z-score on frailty is not significant. Similar to the results from the cross-sectional analysis, the interaction terms in Table 4 do not show consistently significant effects on frailty. In the Supplementary material, we used 2-year and 3-year periods as the long-term exposure measure and found that longterm effects are significantly associated with frailty but short-term exposure (weekly z-score) and interaction terms have no significant effects on frailty (details shown in Tables S9-10). The analysis from GWR data shows there is an association of long-term exposure with frailty score in Table S12. In addition, in Table 4, gender, age, education, marital status and career are significantly associated with frailty; but the coefficients of GDP and population density are not significant.

Table 4 Incidence rate ratio (95\% Confidence Intervals) and random-effect parameters of longitudinal impact of 1-year and weekly exposure to air pollution on frailty among Chinese elderly, CLHLS 2011 \& 2014

\begin{tabular}{lccc}
\hline VARIABLES & $\begin{array}{c}\text { Model 1 } \\
\text { Long-term }\end{array}$ & $\begin{array}{c}\text { Model 2 } \\
\text { Model 1+ short-term }\end{array}$ & $\begin{array}{c}\text { Model 3 } \\
\text { Model 2 + Long- \# } \\
\text { short-term }\end{array}$ \\
\hline $\begin{array}{l}\text { Long-term (1-year) (ref: AQI 1(good)) } \\
\text { AQI 2 (Moderate) }\end{array}$ & $1.212^{* *}$ & $1.218^{* *}$ & $1.217^{* *}$ \\
& $(1.071-1.370)$ & $(1.077-1.377)$ & $(1.076-1.375)$ \\
AQI 3 (Unhealthy) & $1.246^{* * *}$ & $1.254^{* * *}$ & $1.246^{* * *}$ \\
& $(1.099-1.413)$ & $(1.106-1.422)$ & $(1.099-1.413)$ \\
AQI 4 (Very unhealthy) & $1.255^{* * *}$ & $1.269^{* * *}$ & $1.233^{* *}$ \\
Short-term & $(1.098-1.434)$ & $(1.110-1.452)$ & $(1.076-1.413)$ \\
Z-score (Weekly) & & 1.023 & $0.911^{*}$ \\
Interaction terms & & $(0.994-1.054)$ & $(0.835-0.995)$ \\
Weekly z-score \# AQI 2 & & & $1.148^{* *}$ \\
Weekly z-score \# AQI 3 & & & $(1.044-1.264)$ \\
nat & & & $1.146^{* *}$
\end{tabular}


Weekly z-score \# AQI 4

$$
\text { Female (ref: Male) }
$$

Age

Age \# Age

Educated

(ref: no schooling)

Career

(ref: Blue-collar)

Self-rated economic (ref: Rich)

Median

Poor

Marriage (ref: Married)

Single

Widowed

Logarithm of GDP

Logarithm of

Population density

Constant

Year of 2014 (ref: 2011)

Random-effect parameters

Between-city Variance

Between-individual Variance

$1.119 * * *$

(1.080 - 1.160)

$1.025^{*}$

(1.002 - 1.047)

1.000

$(1.000-1.000)$

$0.929 * * *$

(0.894 - 0.966)

$1.159 * * *$

(1.112 - 1.208)

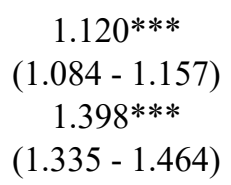

$1.120 * *$

(1.029 - 1.219)

$1.048 * *$

(1.011 - 1.085)

1.028

(0.956 - 1.106)

1.018

(0.949 - 1.092)

$0.199 * *$

(0.0605 - 0.652)

$1.081 * * *$

(1.042 - 1.121)

$0.017 * * *$

$(0.008-0.025)$

$0.281 * * *$

(0.264 - 0.298)
1.120 ***

$(1.080-1.161)$

$1.024 *$

(1.002 - 1.047)

1.000

$(1.000-1.000)$

$0.930 * * *$

(0.894 - 0.966)

$1.159 * * *$

(1.112 - 1.208)

1.120 ***

(1.084 - 1.158)

$1.398 * * *$

(1.336 - 1.464)

$1.119 * *$

(1.028 - 1.218)

$1.048 * *$

(1.011 - 1.085)

1.028

(0.955 - 1.106)

1.020

(0.951 - 1.093)

$0.199 * *$

(0.0607 - 0.651)

$1.071 * * *$

(1.031 - 1.112)

$0.016 * * *$

(0.008 - 0.025)

$0.281 * * *$

(0.2614 - 0.297)
(1.038 - 1.266)

1.054

$(0.928-1.197)$

$1.124 * * *$

(1.084 - 1.165)

1.026*

(1.004 - 1.049)

1.000

$(1.000-1.000)$

$0.933 * * *$

(0.897 - 0.969)

$1.161 * * *$

(1.114 - 1.210)

$1.121 * * *$

(1.085 - 1.158)

$1.400 * * *$

(1.337 - 1.465)

$1.119 * *$

(1.028 - 1.218)

$1.047 *$

(1.010 - 1.084)

1.029

(0.955 - 1.107)

1.018

(0.949 - 1.091)

$0.203 * *$

$(0.0622-0.665)$

$1.069 * * *$

(1.029 - 1.110)

$0.016^{* * *}$

(0.008-0.024)

$0.280 * * *$

$(0.263-0.296)$

Observations (Individual)

8,753

8,753

8,753

$108+108$

108

Number of cities

Note:

1. City-level variables include AQI, z-score, logarithm of GDP per capita, logarithm of population density;

2. $* * * \mathrm{p}<0.001, * * \mathrm{p}<0.01, * \mathrm{p}<0.05, \# \mathrm{p}<0.1$

328 Additionally, to make the analysis above more robust, we run some similar models but use weekly,

329 monthly and quarterly z-score as the short-term exposure in Table S11. We can see the estimated effect

330 of exposure to long-term air pollution on frailty slightly rises when the measures of short-term exposure

331 refer to different periods, from weekly z-score to quarterly z-score; but short-term fluctuations at a week,

332 a month or a quarter are not significantly associated with frailty even at the $10 \%$ level. 
333

334

335

336

337

338

339

340

341

342

343

344

345

346

To assess whether long-term exposure to air pollution is associated with a more unfavourable change in frailty between CLHLS 2011 and 2014, we set up two random-effects models using the type of AQI change. Table 5 compares the effects of the change in AQI on the frailty index. Model 1 shows that living in an area where AQI moved from 2 to 3,2 to 4, or 3 to 4, compared with living in a constant 'AQI 2' area, is associated with increased frailty scores. Specifically, in Model 1, with AQI worsening from 2 to 4 , the incidence rate of frailty increases by about $21.4 \%(\mathrm{p}=0.000)$, compared with a constant 'AQI 2'. More control variables are added, such as year and other covariates, in Model 2 and Model 3. When controlling all of covariates in Model 3, we can see respondents living in 'AQI 1-1', i.e. a constant low level of AP, decreases frailty risk by $21.6 \%(\mathrm{p}<0.001)$, while those living in 'AQI 3-3', i.e. a constant high level, increases the risk by $19.0 \%(\mathrm{p}=0.028)$, compared with the reference group 'AQI 22'. The same analysis using the GWR-interpolated data shows that the change in AQI is associated with the change in frailty score (Table S13).

Table 5 Incidence rate ratio (95\% Confidence Intervals) of longitudinal impact of 1-year AQI change on frailty among Chinese elderly from random-effects models, CLHLS 2011 \& 2014

\begin{tabular}{lccc}
\hline & Model 1: & Model 2: & Model 3: \\
VARIABLES & Basic & Model 1+year & Model 2+covariates \\
\hline AQI change type (ref: AQI 2-2) & & & \\
AQI 1-1 & $0.853^{*}$ & $0.835^{* *}$ & $0.784^{* * *}$ \\
& $(0.753-0.966)$ & $(0.737-0.947)$ & $(0.698-0.880)$ \\
AQI 3-3 & $1.161 \#$ & 1.145 & $1.190^{*}$ \\
& $(0.976-1.380)$ & $(0.963-1.362)$ & $(1.018-1.390)$ \\
AQI 2-3 & $1.055 \#$ & $1.056 \#$ & $1.117^{* * *}$ \\
& $(0.992-1.123)$ & $(0.992-1.124)$ & $(1.057-1.181)$ \\
AQI 2-4 & $1.214^{* * *}$ & $1.203^{* * *}$ & $1.163^{* * *}$ \\
& $(1.113-1.324)$ & $(1.102-1.313)$ & $(1.075-1.259)$ \\
AQI 3-2 & 0.895 & 0.872 & 0.958 \\
& $(0.696-1.150)$ & $(0.678-1.122)$ & $(0.769-1.195)$ \\
AQI 3-4 & $1.091^{*}$ & $1.081 \#$ & $1.090^{*}$ \\
& $(1.008-1.182)$ & $(0.998-1.172)$ & $(1.013-1.173)$ \\
z-score (Weekly) & $1.164 * * *$ & 1.020 & 1.012 \\
& $(1.129-1.200)$ & $(0.986-1.055)$ & $(0.980-1.046)$ \\
Observations (Individual) & 5,926 & 5,926 & 5,926 \\
Number of cities & 73 & 73 & 73 \\
\hline
\end{tabular}

Note:

1.Model 2 includes time variables;

2.Model 3 includes control variables at individual level include sex, age, age square, marital status, education, self-rated economic, career; City-level variables include AQI, z-score, logarithm of GDP per capita, logarithm of population density and year; 
We conducted cross-sectional and longitudinal analysis among Chinese elderly people based on CLHLS, a national dataset, linked to air pollution monitoring station data, to investigate the association between air pollution at the city level and frailty. We also calculated comprehensive measures to assess and adjust models for long- and short-term AP exposure. We identified that the frailty score among Chinese elderly $65+$ was strongly associated with long-term exposure (1-year) to AP rather than shortterm fluctuations, after individual and neighbourhood characteristics are controlled. Moreover, we also established that living in a city with worsening AP over a three-year period, compared with one where air pollution was stable, was associated with a higher incident frailty score, suggesting that increasing air pollution could exacerbate the ageing process.

It is already well established that air pollution has an impact on elderly health in terms of individual diseases, (Zeng et al., 2010), and others have established that in sub-populations AP is linked to the development of frailty (Lüscher, 2017; Myers et al., 2013). This is the first study to our knowledge to establish a longitudinal link between air pollution and frailty in the general elderly population. Previous research about AP and frailty has not explored the role of long- and short-term exposure. As expected, due to the chronic nature of many of the indicators in the frailty index, long-term exposure was the dominant influence. However, this lack of association could also be related to the way health data were collected. Given a source of health data that captured health shocks more adequately, such as acute hospital admissions, it is plausible that short-term exposures may influence some components of frailty. The associations between frailty and other covariates showed expected links with sex (women have a higher frailty score than men), education (people with no schooling have a higher frailty score) and SES (people with lower SES have a higher frailty score). However, it is interesting that respondents with white-collar jobs before their retirement are much frailer than those who had worked in blue-collar jobs, which seems to be incompatible with previous findings, because the effects of career should be same to

372 the effects of education and economic status (Goodman et al., 2011; O’Neill et al., 2003). Explanations

373 for this contradictory result should consider the social structure in China. Respondents with white-collar 
jobs as their main occupation before retirement typically live in cities because most of them are welleducated or working for government, whereby work opportunities depend on education and political loyalty before the 1980s in China (Walder, 1995). In addition, urban residents have access to more ancillary services to acquire health diagnoses than their rural counterparts (Mueser et al., 2001), which might explain an underestimation of the incidence rate of diseases among rural residents. Popkin et al. (1995) proposed that urban residents or high-income populations are likely to have higher fat intake and lower physical activity. There is evidence showing urban adults in China have a higher probability of being obese (Chen et al., 2011) and having hypertension (Xiaohui Hou, 2008). All of those reasons can explain the association of white-collar jobs with higher risks of being frail in this study. Note that all interactions between AP and these socio-demographic factors were insignificant, meaning that the impact of AP on health is uniform regardless of socio-economic status.

In this study, frailty is positively related to long-term exposure to air pollution rather than short-term fluctuations. This is partly contrary to what has been found in previous studies, which identified shortterm exposure to air pollution are associated with hospitalisation due to cardiovascular and respiratory diseases (Raza et al., 2018), which are components of our frailty index. For example, Bedada et al. (2012) found a positive association between short-term exposure to sulphur dioxide and stroke. As another example, an increase of weekly exposure to ozone was associated with a decrease of cardiopulmonary function (Karakatsani et al., 2017). However, it is likely that chronic conditions based on survey self-reports are less sensitive to these recent short-term effects, which could explain why short-term AP fluctuations were not found to be significant.

This study has not found a consistent interaction effect of long- and short-term exposure on frailty among Chinese elderly people. However, this finding provides a more solid evidence to examine the effect of long-term exposure than previous researches. For example, Zhang et al. (2018) recognised that exploring the impact of exposure to AP on cognitive ability should consider the cumulative and transitory exposure AP together. However, they neglected the variance of cumulative exposure to AP and the collinearity between the mean of cumulative exposure and the mean of transitory exposure to 
400 AP. In this study, using a z-score to operationalize and control short-term exposure to AP more

401 accurately measures the association between long-term exposure and frailty.

402 Our study has several methodological advantages over previous studies. First, the linkages of survey 403 data with air quality data were established using exact interview date and locations, enabling us to accurately identify temporal trends in air pollution, even if interview dates varied between respondents. We also used a comprehensive validated frailty index. Moreover, we exploited the available AP data to measure both the average AQI exposure and the level of AQI short-term fluctuation through the AQI z-score. Third, the samples in this study were aged 65 and more, a population who are vulnerable to exposure to air pollution, rarely migrating and moving their residences, hardly changing their socioeconomic status. Thus, the analysis was more likely to identify associations of exposure to air when they are unaffected by time varying confounding. Finally, this study used a GWR method to interpolate missing air pollution data, which provides reassurance as to the robustness of the results, and that the complete case analysis was not biased. GWR contains more parameters (spatial information and socioeconomic factors) for interpolation, which improves previous imputation or interpolation approaches.

Several limitations should be considered in this study. First, our analyses do not include all of the CLHLS sample, only using $60 \%$ respondents due to missing of AQI data, which cannot be nationally representative. However, robustness checks using GWR to interpolate missing data suggested our sample did not lead to biased estimates. Second, our AQI data is city-level; however, there is likely to be variation of AQI within a city. This measure cannot compare the difference between respondents within the same city, despite using the multilevel modelling in this study. Third, the explanatory variable is a composite index of AP rather than specific air pollutants (such as PM10, ozone, SO2 etc.), and we cannot separate the effect of each component of AQI. Nevertheless, numerous studies have used AQI and found that it is a robust estimate of health risks (Li et al., 2015; Stieb et al., 2005). Fourth, as only two waves of data are used in this paper, we are unable to truly understand trajectories of frailty (for that, we need 3 waves, and our linked data are not sufficient). Furthermore, some unmeasured timevariant variables, such as health or social-environmental factors, cannot be ruled out in this study, which 
might affect the relationship we estimated. In addition, we are unable to address survival bias, a perennial question in epidemiology. Finally, participation bias should be noted as all indicators of frailty are self-rated, and some people could be suffering from conditions but not diagnosed. Therefore, our estimations possibly underestimate the level of frailty.

\section{Conclusions}

This study expands the evidence that long-term exposure to air pollution contribute to higher incidence of frailty among Chinese elderly people, when controlled for sex, age, self-rated economic status, education, career, marital status, regional factors (GDP per capita and population density) and interview time. Moreover, it suggests that worsening air quality may influence poorer frailty trajectories. Further research is needed using a longer time span of data to understand how the interaction between shortand long-term exposure to air pollution accumulate to affect elderly health trajectories. Our results highlight the importance of improving air pollution for successful healthy ageing.

\section{Declaration of Competing Interest}

All authors declared no conflicts of interests.

\section{Acknowledgments}

This study is supported by China Scholarship Council (CSC), People's Republic of China, and Population and Health Research Group, School of Geography and Sustainable Development, University of St Andrews, UK. We are grateful to Prof. Hill Kulu who made some critical suggestions for the final manuscript.

\section{References}

Bai, L., Weichenthal, S., Kwong, J.C., Burnett, R.T., Hatzopoulou, M., Jerrett, M., van Donkelaar, A., Martin, R. V, Van Ryswyk, K., Lu, H., Kopp, A., Chen, H., 2019. Associations of Long-Term Exposure to Ultrafine Particles and Nitrogen Dioxide With Increased Incidence of Congestive Heart Failure and Acute Myocardial Infarction. Am. J. Epidemiol. 188, 151-159. https://doi.org/10.1093/aje/kwy194

Bedada, G.B., Smith, C.J., Tyrrell, P.J., Hirst, A.A., Agius, R., 2012. Short-term effects of ambient 
particulates and gaseous pollutants on the incidence of transient ischaemic attack and minor stroke: A case-crossover study. Environ. Heal. 11, 77. https://doi.org/10.1186/1476-069X-11-77

Brunekreef, B., Holgate, S.T., 2002. Air pollution and health. Lancet 360, 1233-1242. https://doi.org/10.1016/S0140-6736(02)11274-8

Cesari, M., Gambassi, G., Van Kan, G.A., Vellas, B., 2014. The frailty phenotype and the frailty index: Different instruments for different purposes. Age Ageing 43, 10-12. https://doi.org/10.1093/ageing/aft160

Charafeddine, R., Boden, L.I., 2008. Does income inequality modify the association between air pollution and health? Environ. Res. 106, 81-88. https://doi.org/10.1016/j.envres.2007.09.005

Chen, T.-J., Modin, B., Ji, C.-Y., Hjern, A., 2011. Regional, socioeconomic and urban-rural disparities in child and adolescent obesity in China: a multilevel analysis. Acta Paediatr. 100, 1583-1589. https://doi.org/10.1111/j.1651-2227.2011.02397.x

Cochran, L.S., Pielke, R.A., Kovács, E., 1992. Selected international receptor-based air quality standards. J. Air Waste Manag. Assoc. 42, 1567-1572. https://doi.org/10.1080/10473289.1992.10467099

Dauchet, L., Hulo, S., Cherot-Kornobis, N., Matran, R., Amouyel, P., Edmé, J.L., Giovannelli, J., 2018. Short-term exposure to air pollution: Associations with lung function and inflammatory markers in non-smoking, healthy adults. Environ. Int. 121, 610-619. https://doi.org/10.1016/j.envint.2018.09.036

Ebenstein, A., Fan, M., Greenstone, M., He, G., Yin, P., Zhou, M., 2015. Growth, pollution, and life expectancy: China from 1991-2012, in: American Economic Review. pp. 226-231. https://doi.org/10.1257/aer.p20151094

Eckel, S.P., Louis, T.A., Chaves, P.H.M., Fried, L.P., Margolis, A.H.G., 2012. Modification of the association between ambient air pollution and lung function by frailty status among older adults in the cardiovascular health study. Am. J. Epidemiol. 176, 214-223. https://doi.org/10.1093/aje/kws001

Fang, E.F., Scheibye-Knudsen, M., Jahn, H.J., Li, J., Ling, L., Guo, H., Zhu, X., Preedy, V., Lu, H., Bohr, V.A., Chan, W.Y., Liu, Y., Ng, T.B., 2015. A research agenda for aging in China in the 21st century. Ageing Res. Rev. 24, 197-205. https://doi.org/10.1016/J.ARR.2015.08.003

Fougère, B., Vellas, B., Billet, S., Martin, P.J., Gallucci, M., Cesari, M., 2015. Air Pollution modifies the association between successful and pathological aging throughout the frailty condition. Ageing Res. Rev. 24, 299-303. https://doi.org/10.1016/J.ARR.2015.09.004

Fried, L.P., Tangen, C.M., Walston, J., Newman, A.B., Hirsch, C., Gottdiener, J., Seeman, T., Tracy, R., Kop, W.J., Burke, G., McBurnie, M.A., 2001. Frailty in Older Adults: Evidence for a Phenotype. Journals Gerontol. Ser. A Biol. Sci. Med. Sci. 56, M146-M157. https://doi.org/10.1093/gerona/56.3.m146

García-Esquinas, E., Rodríguez-Artalejo, F., 2017. Environmental Pollutants, Limitations in Physical Functioning, and Frailty in Older Adults. Curr. Environ. Heal. reports. https://doi.org/10.1007/s40572-017-0128-1

Gerber, Y., Myers, V., Broday, D.M., Steinberg, D.M., Yuval, Koton, S., Drory, Y., 2014. Frailty status modifies the association between air pollution and post-myocardial infarction mortality: A 20-year follow-up study. J. Am. Coll. Cardiol. https://doi.org/10.1016/j.jacc.2014.01.026

Goodman, A., Wilkinson, P., Stafford, M., Tonne, C., 2011. Characterising socio-economic inequalities in exposure to air pollution: A comparison of socio-economic markers and scales of measurement. Health Place 17, 767-774. https://doi.org/10.1016/J.HEALTHPLACE.2011.02.002 
Gu, D., Dupre, M.E., Sautter, J., Zhu, H., Liu, Y., Yi, Z., 2009. Frailty and mortality among chinese at advanced ages. Journals Gerontol. - Ser. B Psychol. Sci. Soc. Sci. 64, 279-289. https://doi.org/10.1093/geronb/gbn009

Gu, J., Chao, J., Chen, W., Xu, H., Wu, Z., Chen, H., He, T., Deng, L., Zhang, R., 2017. Multimorbidity in the community-dwelling elderly in urban China. Arch. Gerontol. Geriatr. 68, 62-67. https://doi.org/10.1016/j.archger.2016.09.001

Jones, D.M., Song, X., Rockwood, K., 2004. Operationalizing a Frailty Index from a Standardized Comprehensive Geriatric Assessment. J. Am. Geriatr. Soc. 52, 1929-1933. https://doi.org/10.1111/j.1532-5415.2004.52521.x

Kampa, M., Castanas, E., 2008. Human health effects of air pollution. Environ. Pollut. 151, 362-367. https://doi.org/10.1016/J.ENVPOL.2007.06.012

Karakatsani, A., Samoli, E., Rodopoulou, S., Dimakopoulou, K., Papakosta, D., Spyratos, D., Grivas, G., Tasi, S., Angelis, N., Thirios, A., Tsiotsios, A., Katsouyanni, K., 2017. Weekly personal ozone exposure and respiratory health in a panel of Greek schoolchildren. Environ. Health Perspect. 125, 1-7. https://doi.org/10.1289/EHP635

Kojima, G., Iliffe, S., Walters, K., 2018. Frailty index as a predictor of mortality: a systematic review and meta-analysis. Age Ageing 47, 193-200. https://doi.org/10.1093/ageing/afx162

Lei, X., Sun, X., Strauss, J., Zhao, Y., Yang, G., Hu, P., Hu, Y., Yin, X., 2014. Health outcomes and socio-economic status among the mid-aged and elderly in China: Evidence from the CHARLS national baseline data. J. Econ. Ageing 3, 29-43. https://doi.org/10.1016/j.jeoa.2014.05.001

Li, L., Lin, G.Z., Liu, H.Z., Guo, Y., Ou, C.Q., Chen, P.Y., 2015. Can the Air Pollution Index be used to communicate the health risks of air pollution? Environ. Pollut. 205, 153-160. https://doi.org/10.1016/j.envpol.2015.05.038

Liu, C., Chen, R., Zhao, Y., Ma, Z., Bi, J., Liu, Y., Meng, X., Wang, Y., Chen, X., Li, W., Kan, H., 2017. Associations between ambient fine particulate air pollution and hypertension: A nationwide cross-sectional study in China. Sci. Total Environ. 584-585, 869-874. https://doi.org/10.1016/J.SCITOTENV.2017.01.133

Liu, C., Yang, C., Zhao, Y., Ma, Z., Bi, J., Liu, Y., Meng, X., Wang, Y., Cai, J., Kan, H., Chen, R., 2016. Associations between long-term exposure to ambient particulate air pollution and type 2 diabetes prevalence, blood glucose and glycosylated hemoglobin levels in China. Environ. Int. 92-93, 416-421. https://doi.org/10.1016/j.envint.2016.03.028

Liu, H., Liu, S., Xue, B., Lv, Z., Meng, Z., Yang, X., Xue, T., Yu, Q., He, K., 2018. Ground-level ozone pollution and its health impacts in China. Atmos. Environ. 173, 223-230. https://doi.org/10.1016/J.ATMOSENV.2017.11.014

Liu, R., Young, M.T., Chen, J.-C., Kaufman, J.D., Chen, H., 2016. Ambient Air Pollution Exposures and Risk of Parkinson Disease. Environ. Health Perspect. 124, 1759-1765. https://doi.org/10.1289/EHP135

Lüscher, T.F., 2017. Frontiers of Prevention: Pollution, Infection, Cognitive Function and Frailty. Eur. Heart J. 38, 3179-3182. https://doi.org/10.1093/eurheartj/ehx680

Ma, Z., Hu, X., Sayer, A.M., Levy, R., Zhang, Q., Xue, Y., Tong, S., Bi, J., Huang, L., Liu, Y., 2016. Satellite-based spatiotemporal trends in PM2.5concentrations: China, 2004-2013. Environ. Health Perspect. 124, 184-192. https://doi.org/10.1289/ehp.1409481

Ministry of Ecology and Environment of China, 2012. Technical Regulation on Ambient Air Quality Index [WWW Document]. URL https://web.archive.org/web/20190713234941/http://kjs.mee.gov.cn/hjbhbz/bzwb/jcffbz/201203/ W020120410332725219541.pdf (accessed 5.2.20). 
Mueser, K.T., Essock, S.M., Drake, R.E., Wolfe, R.S., Frisman, L., 2001. Rural and urban differences in patients with a dual diagnosis. Schizophr. Res. 48, 93-107. https://doi.org/10.1016/S09209964(00)00065-7

Myers, V., Broday, D.M., Steinberg, D.M., Yuval, Drory, Y., Gerber, Y., 2013. Exposure to particulate air pollution and long-term incidence of frailty after myocardial infarction. Ann. Epidemiol. 23, 395-400. https://doi.org/10.1016/J.ANNEPIDEM.2013.05.001

National Bureau of Statistics of China, 2010. Tabulation on the 2010 population census of China by county, 2nd ed. China Statistics Press.

O’Neill, M.S., Jerrett, M., Kawachi, I., Levy, J.I., Cohen, A.J., Gouveia, N., Wilkinson, P., Fletcher, T., Cifuentes, L., Schwartz, J., Workshop on Air Pollution and Socioeconomic Conditions, W. on A.P. and S., 2003. Health, wealth, and air pollution: advancing theory and methods. Environ. Health Perspect. 111, 1861-70.

Popkin, B.M., Paeratakul, S., Zhai, F., Ge, K., 1995. Dietary and Environmental Correlates of Obesity in a Population Study in China. Obes. Res. 3, 135s-143s. https://doi.org/10.1002/j.15508528.1995.tb00456.x

Ranft, U., Schikowski, T., Sugiri, D., Krutmann, J., Krämer, U., 2009. Long-term exposure to trafficrelated particulate matter impairs cognitive function in the elderly. Environ. Res. 109, 10041011. https://doi.org/10.1016/j.envres.2009.08.003

Raza, A., Dahlquist, M., Lind, T., Ljungman, P.L.S., 2018. Susceptibility to short-term ozone exposure and cardiovascular and respiratory mortality by previous hospitalizations. Environ. Heal. 17, 37. https://doi.org/10.1186/s12940-018-0384-z

Richardson, E.A., Pearce, J., Kingham, S., 2011. Is particulate air pollution associated with health and health inequalities in New Zealand? Heal. Place 17, 1137-1143. https://doi.org/10.1016/j.healthplace.2011.05.007

Ruggieri, M., Plaia, A., 2012. An aggregate AQI: Comparing different standardizations and introducing a variability index. Sci. Total Environ. 420, 263-272. https://doi.org/10.1016/j.scitotenv.2011.09.019

Scheers, H., Nawrot, T.S., Nemery, B., Casas, L., 2018. Changing places to study short-term effects of air pollution on cardiovascular health: a panel study. Environ. Heal. 17, 80. https://doi.org/10.1186/s12940-018-0425-7

Signoretta, P.E., Buffel, V., Bracke, P., 2019. Mental wellbeing, air pollution and the ecological state. Health Place 57, 82-91. https://doi.org/10.1016/J.HEALTHPLACE.2019.03.003

Stieb, D.M., Doiron, M.S., Blagden, P., Burnett, R.T., 2005. Estimating the Public Health Burden Attributable to Air Pollution: An Illustration Using the Development of an Alternative Air Quality Index. J. Toxicol. Environ. Heal. Part A 68, 1275-1288. https://doi.org/10.1080/15287390590936120

Sun, R., Gu, D., 2008. Air pollution, economic development of communities, and health status among the elderly in urban China. Am. J. Epidemiol. 168, 1311-1318. https://doi.org/10.1093/aje/kwn260

United Nations, 2019. World Population Prospects 2019 [WWW Document]. URL https://population.un.org/wpp/Graphs/Probabilistic/POP/65plus/156 (accessed 5.2.20).

Walder, A.G., 1995. Career Mobility and the Communist Political Order. Am. Sociol. Rev. 60, 309. https://doi.org/10.2307/2096416

Walston, J., Hadley, E.C., Ferrucci, L., Guralnik, J.M., Newman, A.B., Studenski, S.A., Ershler, W.B., Harris, T., Fried, L.P., 2006. Research Agenda for Frailty in Older Adults: Toward a 
Better Understanding of Physiology and Etiology: Summary from the American Geriatrics Society/National Institute on Aging Research Conference on Frailty in Older Adults. J. Am. Geriatr. Soc. 54, 991-1001. https://doi.org/10.1111/j.1532-5415.2006.00745.x

Wang, C., Xu, J., Yang, L., Xu, Y., Zhang, Xiangyan, Bai, C., Kang, J., Ran, P., Shen, H., Wen, F., Huang, K., Yao, W., Sun, T., Shan, G., Yang, T., Lin, Y., Wu, S., Zhu, J., Wang, R., Shi, Z., Zhao, J., Ye, X., Song, Y., Wang, Q., Zhou, Y., Ding, L., Yang, T., Chen, Y., Guo, Y., Xiao, F., Lu, Y., Peng, X., Zhang, B., Xiao, D., Chen, C.S., Wang, Z., Zhang, H., Bu, X., Zhang, Xiaolei, An, L., Zhang, S., Cao, Z., Zhan, Q., Yang, Y., Cao, B., Dai, H., Liang, L., He, J., 2018. Prevalence and risk factors of chronic obstructive pulmonary disease in China (the China Pulmonary Health [CPH] study): a national cross-sectional study. Lancet 391, 1706-1717. https://doi.org/10.1016/S0140-6736(18)30841-9

Wang, Y., Ying, Q., Hu, J., Zhang, H., 2014. Spatial and temporal variations of six criteria air pollutants in 31 provincial capital cities in China during 2013-2014. Environ. Int. 73, 413-422. https://doi.org/10.1016/J.ENVINT.2014.08.016

Xiao, S., Liu, R., Wei, Y., Feng, L., Lv, X., Tang, F., 2016. Air pollution and blood lipid markers levels: Estimating short and long-term effects on elderly hypertension inpatients complicated with or without type 2 diabetes. Environ. Pollut. 215, 135-140. https://doi.org/10.1016/j.envpol.2016.05.007

Xiaohui Hou, 2008. Urban-Rural Disparity of Overweight, Hypertension, Undiagnosed Hypertension, and Untreated Hypertension in China. Asia Pacific J. Public Heal. 20, 159-169. https://doi.org/10.1177/1010539507312306

Yang, B.-Y., Qian, Z., Howard, S.W., Vaughn, M.G., Fan, S.-J., Liu, K.-K., Dong, G.-H., 2018. Global association between ambient air pollution and blood pressure: A systematic review and meta-analysis. Environ. Pollut. 235, 576-588. https://doi.org/10.1016/J.ENVPOL.2018.01.001

Yang, F., Gu, D., 2016. Predictability of frailty index and its components on mortality in older adults in China. BMC Geriatr. 16, 1-9. https://doi.org/10.1186/s12877-016-0317-z

Zeng, Y., Feng, Q., Hesketh, T., Christensen, K., Vaupel, J.W., 2017. Survival, disabilities in activities of daily living, and physical and cognitive functioning among the oldest-old in China: a cohort study. Lancet 389, 1619-1629. https://doi.org/10.1016/S0140-6736(17)30548-2

Zeng, Y., Gu, D., Purser, J., Hoenig, H., Christakis, N., 2010. Associations of environmental factors with elderly health and mortality in china. Am. J. Public Health 100, 298-305. https://doi.org/10.2105/AJPH.2008.154971

Zhang, J., Mauzerall, D.L., Zhu, T., Liang, S., Ezzati, M., Remais, J. V, 2010. Environmental health in China: progress towards clean air and safe water. Lancet. https://doi.org/10.1016/S01406736(10)60062-1

Zhang, Xin, Chen, X., Zhang, Xiaobo, 2018. The impact of exposure to air pollution on cognitive performance. Proc. Natl. Acad. Sci. 115, 9193-9197. https://doi.org/10.1073/PNAS.1809474115

Zhong, B.L., Chen, S.L., Tu, X., Conwell, Y., 2017. Loneliness and cognitive function in older adults: Findings from the chinese longitudinal healthy longevity survey. Journals Gerontol. - Ser. B Psychol. Sci. Soc. Sci. https://doi.org/10.1093/geronb/gbw037 